\title{
The characterization of microcapsules printed by screen printing and coating technology
}

\begin{abstract}
Depending on the microcapsules functionality, i.e. encapsulated core material, nowadays microcapsules are used in various fields of application, such as in medicine, pharmacy, agriculture, construction industry, chemical industry, food industry, biotechnology, electronics, as well as in printing and textile industry. In order to fulfil their basic purpose, microcapsules have to be transferred onto the target areas of the substrate material without damage, using different deposition techniques, mostly coating and printing techniques. The aim of this research is to firstly investigate the physical characteristics of the two selected fragranced microcapsules, applied by screen printing and coating technique, and secondly to determine how their addition in the selected three varnishes affected the basic characteristics of the prints. Fragranced microcapsules were before printing and coating adequately premixed with the selected varnish. The research revealed that the characteristics of the fragranced microcapsules and the varnishes as well as the used application techniques significantly affected the behaviour of the fragranced microcapsules and their deposition in the printed varnish layer as well as on the characteristics of the prints.
\end{abstract}

\section{KEY WORDS}

fragranced microcapsules, screen printing, coating, varnish, foil

\author{
Rastko Milošević ${ }^{1}$ \\ Nemanja Kašiković ${ }^{1}$ \\ Tomislav Cigula², Urška \\ Stanković Elesini ${ }^{3}$ and \\ Raša Urbas ${ }^{3}$ \\ ${ }^{1}$ University of Novi Sad, Faculty of \\ Technical Sciences, Department of \\ Graphic Engineering and Design, \\ Serbia \\ ${ }^{2}$ University of Zagreb, Faculty \\ of Graphic Arts, Department of \\ Printing Plates, Croatia \\ ${ }^{3}$ University of Ljubljana, Faculty of \\ Natural Sciences and Engineering, \\ Department of Textiles, Graphic \\ Arts and Design, Slovenia
}

Corresponding author: Rastko Milošević e-mail:rastko.m@uns.ac.rs

First recieved: 11.03.2017. Accepted: 24.05.2017.

\section{Introduction}

The graphic industry is one of the first that began to utilize microcapsules, which are nowadays used in various fields of applications such as: medicine, pharmacy, agriculture, construction industry, chemical industry, food industry, biotechnology, cosmetic industry, photography, electronics, textile and printing industry (Boh et al., 1999; Arshady \& Boh, 2003; Boh, 2007; Poncelet $\&$ Boh, 2008). Microcapsules are tiny spheres that usually consist of two parts: the core and the shell (Gosh, 2000). Microencapsulation enables the core material to reach the "target" areas without getting affected by the surroundings, while the microcapsule microscopic size enables the consumption of the very small active agent quantity (Gosh, 2000; Dubey et al., 2009; McShane \& Ritter, 2010; Microtek Laboratories Inc., 2015). One of the simplest and the most frequently used encapsulation method in the graphic industry is "in situ" polymerization, which provides high active agent loadings and smoothly shaped microcapsules with good mechanical properties (Kuković \& Knez, 1998; Gosh, 2000; Nelson, 2001; Starešinič, Šumiga \& Boh, 2011; Ocepek et al., 2012). Microcapsules used in printing applications can be activated by the use of different mechanisms, which are mainly based on external pressure, abrasion and heat or light activation (Gosh, 2000; Nelson, 2001; Boh \& Šumiga, 2008; Sensor Products Inc., 2015). 
The progress in the printing technology, in addition to the visual and the tactile sensations, also enables the perception of scent, by applying various microcapsules containing fragrances (Rose, 2007). Because the fragrances are highly volatile substances, the encapsulation represents a necessary step for ensuring longer activity time, the protection against the environment, and the controlled release of encapsulated fragrance (MikroCaps, 2013; Pavlović et al. 2014). Microcapsules, which can be applied on different printing substrates at the end of the printing processes via coating or spraying, can enrich their properties and end use. They can also be incorporated into the material itself, or simply transferred onto the substrate using various printing techniques such as screen printing, sheet-fed and web offset printing, gravure, flexography, pad printing, inkjet and xerography (Gosh, 2000; Goetzendorf-Grabowska, Krolikowska \& Gadzinowski 2004; Chovancova, Pekarovicova \& Fleming, 2005, Goetzendorf-Grabowska et al., 2008; Rodrigues et al., 2009; Milošević et al., 2016). The main advantage of the printing technology is that the microcapsules are evenly applied to the target areas (Starešinič, Šumiga \& Boh, 2011), due to the fact that they are usually premixed into the ready-to-use inks, conventional, UV and plastisol inks, or with the printing varnish (Maekawa et al., 1975; Kipphan, 2001; Kulčar et al., 2010; Pavlović et al., 2014). One of the main problems, which can in some cases occur in the printing process of the microcapsules, is their clustering, which can lead to uneven spatial distribution of the used microcapsules in the printed ink/varnish layer, and as such negatively effect the visual appearance and the functionality of the prints (Chen 2014; Urbas et al., 2014).

Regarding the assessment of the basic microcapsules physical properties, such as morphology, microcapsule formation, size and volume distributions, they can be determined by optical, scanning electron microscopy (SEM) or transmission electron microscopy (TEM) in the combination with the appropriate image analysis software (Peña et al., 2009; Rodrigues et al., 2009; Urbas et al., 2015).

The aim of this research was to determine the basic physical characteristics of two types of used fragranced microcapsules - fragranced microcapsules in water suspension and dry fragranced microcapsules, in which scented fragrances were encapsulated. Both types of microcapsules were premixed at the same mass concentration of $1 \%$ with the appropriate varnish (water-based or oil-based varnish) and subsequently printed onto the printing substrate (transparent foil), using screen printing and coating technique. The effects of different factors e.g. the addition of the fragranced microcapsules, their properties as well as the properties of three selected varnishes (two water-based and one oil-based), and the influence of the microcapsule's deposition techniques on the behavior of the selected fragranced microcapsules in the printed varnish layers and on the characteristics of the prints itself were investigated.

\section{Materials and Methods}

For the purpose of the research, samples were printed with two different printing techniques - screen printing and coating technique, on the same printing substrate. For printing, three types of varnishes (two waterbased and an oil-based varnish) were used. In those varnishes, adequate types of the fragranced microcapsules - in water suspension and dry, were premixed.

\section{Materials}

Specific properties of the used materials are presented in the continuation.

\section{Printing substrate}

As a printing substrate, a commercially available transparent foil was used. Due to the lack of technical information, thickness, grammage and surface roughness were determined by the appropriate standard test methods. Results are presented in the continuation.

\section{Microcapsules}

In the research two types of microcapsules were used:

- fragranced microcapsules in water suspension (microcapsule designation $\mathrm{MC}_{1}$ ) and

- dry fragranced microcapsules (microcapsule designation $\mathrm{MC}_{2}$ ).

\section{The fragranced microcapsules in water suspension} (MC) were mono-core, made by modified in situ polymerization method (Šumiga, 2013). The microcapsule core material was made of different essential oils combination with the fragrances of sage, rosemary and lavender, while the microcapsule shell was made of partially methylated trimethylol melamine (Melamin, Slovenia). The polyacrylic polymer was used as the modifying agent/ poly-condensation initiator for the "in situ" polymerization, while the analytical grade sodium hydroxide (Kemika, Croatia) was used for the termination of the poly-condensation reaction and $\mathrm{pH}$ neutralisation. In order to remove the released formaldehyde during the poly-condensation, ammonia (Kemika, Croatia) was added to the suspension of the microcapsules as the scavenger. The modified process of the "in situ" polymerization microencapsulation was performed in a 11 laboratory reactor, equipped with a turbine stirrer in the following stages: (1) preparation of an aqueous solution of modifying agent; (2) emulsification of core material at room temperature with stirrer speed of 1500 rpm for 20 min; (3) addition of partly methylated trimethylol melamine amino-alde- 
hyde prepolymer for shell formation; (4) induction of poly-condensation reaction by raising the temperature to $70-80^{\circ} \mathrm{C}$; (5) poly-condensation process - the formation of microcapsules (approx. 1 hour); (6) termination of poly-condensation; (7) removal of released formaldehyde by addition of ammonia scavenger at $50^{\circ} \mathrm{C}$; and (8) cooling to room temperature (Stankovič - Elesini et al., 2016).

The dry fragranced microcapsules $\left(\mathrm{MC}_{2}\right)$ were monocore as well ( $6 \mu \mathrm{m}$ to $10 \mu \mathrm{m}$ mean size, according to the technical specification of the producer FOLCO SCENT ${ }^{\circledR}$ Printable Scents (Follmann GmbH \& Co. KG, Germany) with the unknown membrane material, encapsulating the essential oil with the scent of the basil.

Specific properties of the fragranced microcapsules e.g. size and volume distribution, fragrance release behaviour and image analyses, are presented in the continuation.

The fragranced microcapsules in water suspension $\left(\mathrm{MC}_{1}\right)$ were mixed with two different water-based varnishes, while the dry fragranced microcapsules $\left(\mathrm{MC}_{2}\right)$ were mixed with oil-based varnish, in order to make prints. Both microcapsule types were added into the varnishes in the same mass concentration of $1 \%$.

\section{Varnishes}

Three different varnishes were used in the research:

- water-based varnish C-375 (varnish designation $\mathrm{V}_{1}$ ), - water-based varnish 2 (varnish designation $\mathrm{V}_{2}$ ), - oil-based varnish C-378 (varnish designation $\mathrm{V}_{3}$ ).

The $\mathbf{C}$-375 water-based printing varnish $\left(\mathbf{V}_{\mathbf{1}}\right)$ is based on stabilised water dispersion of acrylic resins (styrene acrylic emulsion) with the addition of polyethylene wax. It is suitable for the protection of printed packaging in the food industry (without direct contact with the food) and is characterised by high gloss and abrasion resistance (Cinkarna Celje, Slovenija).

The second water-based varnish $\left(\mathbf{V}_{2}\right)$ is based on the acrylic emulsion without the addition of the polyethylene wax. It is a commercially available varnish (from unknown producer), which was selected as a comparison to printing varnish $\mathrm{V}_{1}$.

The $\mathbf{C - 3 7 8}$ varnish $\left(\mathbf{V}_{\mathbf{3}}\right)$ is mineral oil-based varnish (polyurethane resin, nitrocellulose and plasticisers), which is characterised by the high gloss, transparency and abrasion resistance (Cinkarna Celje, Slovenija).

\section{Methods}

Different techniques and testing methods were used for determination of specific properties of printing materials (printing substrate, microcapsules and varnishes) and printed samples (printed without and with selected fragranced microcapsules). Their features are described in the continuation.

\section{Printing techniques}

Two techniques were used - manual screen printing and coating for producing final testing sampes.

Screen printing process. Screen printing mesh had 62 threads/cm, each filament had diameter of 64 $\mu \mathrm{m}$, screen tension was $15 \mathrm{~N}$. Photo emulsion was applied in two layers. Printing form consisted of printing elements in the form of squares $4 \times 4 \mathrm{~cm}$. All samples were printed with one passage of squeegee.

Coating technique. A coater (BYK 4-sided applicator, Germany) that allows maximum deposition thickness of the applied layer $200 \mu \mathrm{m}$ was used for coating. Similar as with the screen printing process, only one layer of varnish was applied (coated) on the printing substrate samples.

After printing and coating, all samples were dried at room temperature $\left(25^{\circ} \mathrm{C}, 55 \%\right.$ relative humidity) for 24 hours.

\section{Properties of the printing material}

In the analyses, specific properties of printing material e.g. printing substrate, microcapsules and varnishes were determined.

For printing substrate following properties were determined: grammage was measured on Mettler AE200 analytical balance (International Organization for Standardization- ISO 536:2012), thickness was measured on the apparatus for measuring thickness (Metrimpex gauge, Hungary) with the measuring surface $1 \mathrm{~cm}^{2}$, pressure $50 \mathrm{kPa}$ and $100 \mathrm{kPa}$ (SIST EN International Organization for Standardization ISO 5084:1996), surface roughness was measured on the Bentsten 3500 (Zehntner GmbH, Swiss) (International Organization for Standardization ISO 8791-2:1990) and optical density was determined with Vipdens150 (Viptronic, Germany).

An image analysis of the selected fragranced microcapsules (morphology and size/volume distribution calculations), surface and cross-section of printing substrate and printed varnish samples (without and with added fragranced microcapsules) was performed by scanning electron microscopy (SEM; JSM 6060 LV, Jeol, Japan) using the standard procedure. Afterwards an image analyses of the SEM micrographs taken under different magnifications was conducted, which enabled the specification of their size and volume distribution.

The software for digital image analysis, ImageJ (ImageJ, 2004), was used for the size measurements of both 
selected types of fragranced microcapsules. Determination of the MC1 diameters based on the 500 measurements on the SEM micrographs (images).

For the selected fragranced microcapsules release behaviour properties were determined. This analysis was performed only for the fragranced microcapsules in water suspension $\left(\mathrm{MC}_{1}\right)$ according to the test by Šumiga (2013). The suspension of the fragranced microcapsules $\mathrm{MC}_{1}$ was added into the aluminium cups $(5 \times 7 \mathrm{~cm}$ in size), which were then placed into a heated drying oven (Binder, Germany) at $135^{\circ} \mathrm{C}$, for 180 minutes. After every 30 minutes, the samples were weighed and placed back into the oven. With the use of equation (1), the release rate of the tested fragranced microcapsules was calculated:

$$
\text { Mass loss }[\%]=\frac{A_{0}-A_{n}}{A_{0}} \cdot 100
$$

where $A_{n}$ presents the weight (g) of the fragranced microcapsules after $n$ minutes of the release behaviour test ( $n=60,90,120,150$, and 180 minutes) and $A_{0}$ presents the weight (g) of the fragranced microcapsule suspension before the release behaviour test.

For the varnishes (without and with added $1 \%$ mass concentration of the both selected fragranced microcapsules), basic characteristics of viscosity and $\mathrm{pH}$ values were determined. The viscosity was measured using Viscotester VT01/02 (Thermo Haake, Germany) and pH values by pH Meter MA 5740 measuring device (Iskra, Slovenia), respectively. With the measured results, values of density were calculated using equation (2):

$$
\rho=m / V\left[g / m^{3}\right]
$$

For surface tension measurements a pendent drop method, using goniometer OCA20 (Dataphysics, Germany), and a plug-in for Fiji ImageJ software (ImageJ, 2004; Daerr \& Mogne, 2016), was chosen.

Properties of the prints

The physical characteristics of the printed samples - thickness and grammage, were determined with previously mentioned methods and apparatus (in chapter 2.2.2), in accordance with the appropriate standards. Surface and cross-section properties of prints were evaluated with image analyses (SEM).

\section{Results and Discussions}

\section{Properties of printing materials}

In the continuation, results of measured specific properties of printing materials are presented.

\section{Printing substrate}

Measured properties of the printing substrate - transparent foil, are presented in Table 1. Image analyses were also performed on the samples of printing substrate for distinguishing its surface properties. In Figure 1 are presented SEM images of the front and the back side surfaces of the transparent foil, which was used for screen printing and coating processes.

\section{Table 1}

Measured properties of printing substrate - foil

\begin{tabular}{l|c}
\hline Measured property & Value \\
\hline Thickness $[\mu \mathrm{m}]$ & 96.90 \\
\hline Grammage $\left[\mathrm{g} / \mathrm{m}^{2}\right]$ & 133.11 \\
\hline Surface roughness $[\mathrm{ml} / \mathrm{min}]$ & 19 \\
front side & 25 \\
back side & 0.0465 \\
\hline Optical density & \\
\hline
\end{tabular}

a)

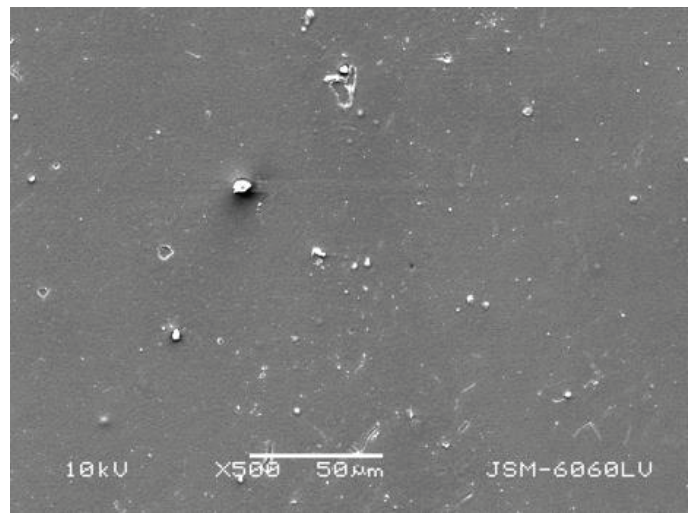

b)

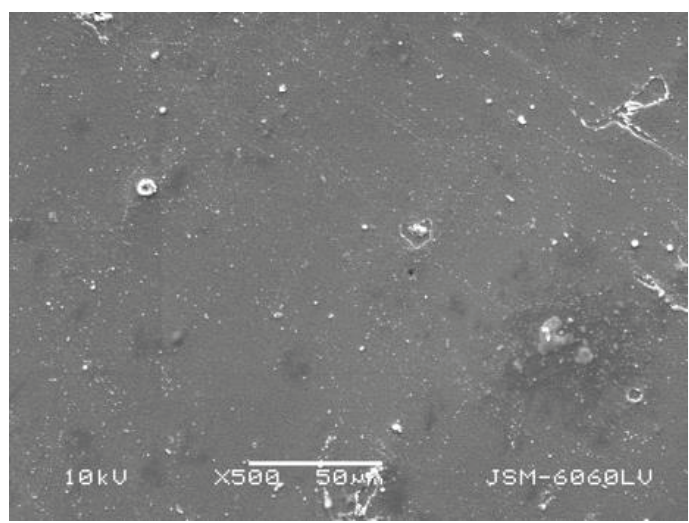

» Figure 1: Front (a) and back (b) side of the printing substrate - transparent foil (SEM; 500x magnification)

Image analyses of the printing substrate - transparent foil, showed that both the front and the back side of the foil surfaces have very similar characteristics. They were relatively smooth, although the back side possessed a slightly larger amount of tiny bumps, scratches and irregularities compared to a somewhat more uniform surface structure of the front side (Figure 1). This was also confirmed by the obtained results of the surface 
roughness measurements (Table 1). Due to small but distinguished differences in the surface characteristics of both sides of the printing substrate, the front side of the foil was selected to be printed and coated.

\section{Microcapsules}

- Size and volume distribution

For easier establishing of the printing varnish properties (without and with the addition of selected fragranced microcapsules) and the assessment of the printing qualities, an analysis of used fragranced microcapsules had to be made.

Figure 2 shows morphology (2a) and size / volume distribution (2b) of the fragranced microcapsules in water suspension $\left(\mathrm{MC}_{1}\right)$, which were used for printing and coating in the combination with the water-based varnishes, $V_{1}$ and $V_{2}$. From Figure $2 a$ can be seen that the fragranced microcapsules of the sample MC1 had very regular, spherical shape and smooth surface, but possessed various sizes, which caused a wide diameter size distribution (Figure 2b). The size distribution curve of the $\mathrm{MC}$, shows an extreme positive skew (blue bars and red curve). $32.87 \%$ of the microcapsules had the diameter of up to $2 \mu \mathrm{m}$, while as much as $77.43 \%$ of the total sampled microcapsules had sizes in the range of 0.5-6 $\mu \mathrm{m}$. The mean diameter of the $\mathrm{MC}_{1}$ was 4.44 $\mu \mathrm{m}$ (stdev. 4.30), while the minimum and maximum recorded microcapsule diameters were $0.67 \mu \mathrm{m}$ and $26.86 \mu \mathrm{m}$, respectively. For the simplification of the microcapsules volume calculation, microcapsules shapes were approximated with the ideal spheres. In contrast to the microcapsule size distribution, the volume distribution (green curve) had an opposite, negative skew, where $1.39 \%$ of all sampled $\mathrm{MC}_{1}$ participated with $32.33 \%$ in the total microcapsules volume amount.

Figure 3 presents morphology ( $3 a$ ) and size / volume distribution (3b) of the dry fragranced microcapsules $\left(\mathrm{MC}_{2}\right)$, which were used for printing and coating processes with the oil-based varnish, $V_{3}$. These $M C_{2}$ microcapsules possessed regular shape and unequal sizes, which was less pronounced compared to the $\mathrm{MC}_{1}$ microcapsules. Hence, $M C_{1}$ microcapsules had much narrower size distribution. $\mathrm{MC}_{2}$ microcapsules had relatively uniform, slightly asymmetric size distribution (blue bars and red curve), where a)

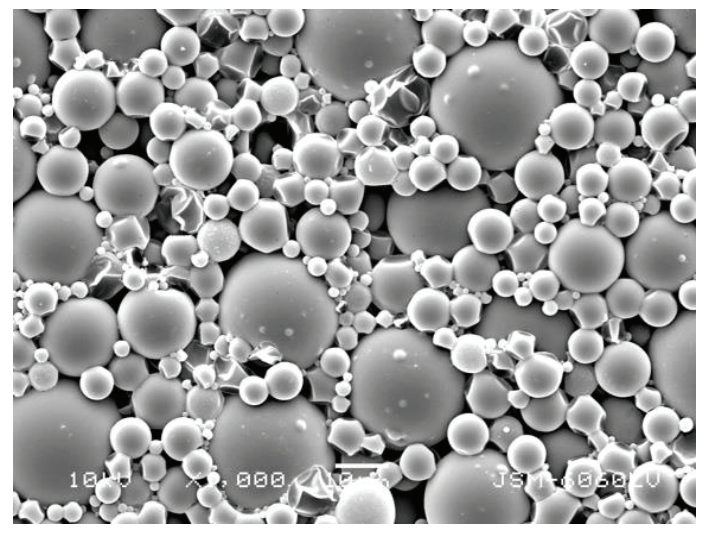

b)

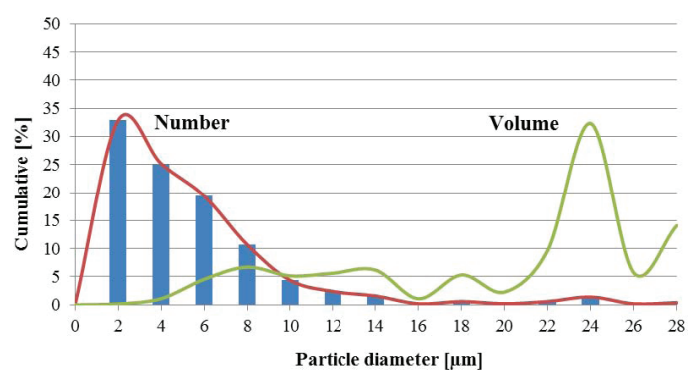

(a) (SEM; 1.000x magnification) with their size 》Figure 2: Fragranced microcapsules in water suspension (MC) (a) (SEM:1.000 and volume distribution (b)

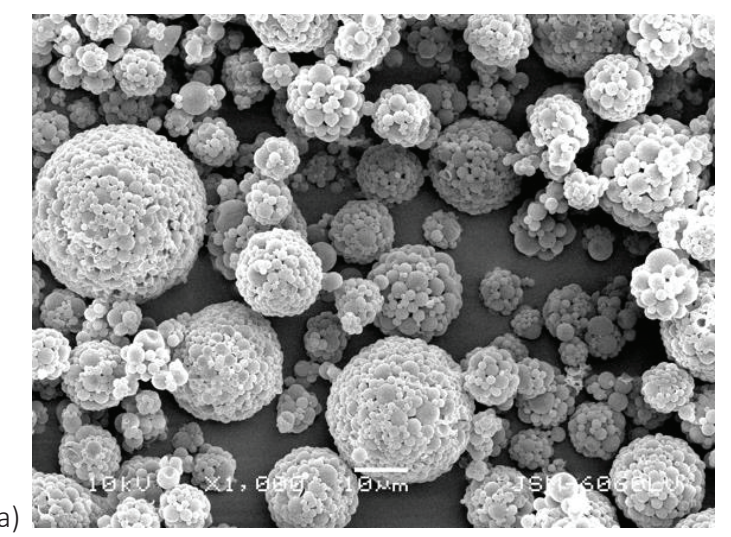

b)

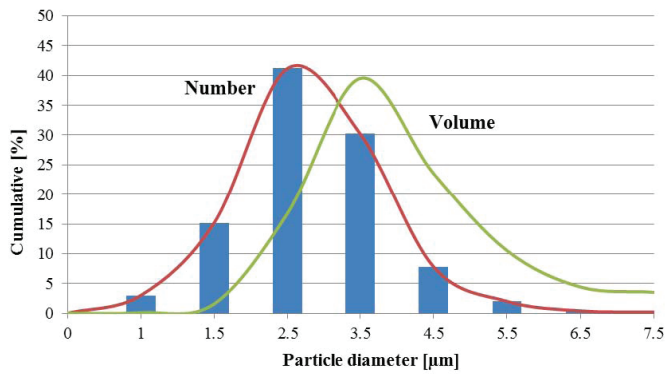

» Figure 3: Dry fragranced microcapsules $\left(\mathrm{MC}_{2}\right)$ (a) (SEM; 1.000x magnification) with their size and volume distribution (b) 
the most $(71.4 \%)$ of microcapsules had the diameter size between $1.5 \mu \mathrm{m}$ and $3.5 \mu \mathrm{m}$. The mean diameter of the sampled $\mathrm{MC}_{2}$ was $2.39 \mu \mathrm{m}$ (stdev. 0.95), where the minimum and the maximum recorded microcapsule diameters were $0.67 \mu \mathrm{m}$ and $7.15 \mu \mathrm{m}$, respectively.

The volume distribution (green curve) of the $\mathrm{MC}_{2}$ was very similar to the microcapsule size distribution, where the microcapsules with the size range between $2.5 \mu \mathrm{m}$ and $4.5 \mu \mathrm{m}$ participated with $63.03 \%$ in the total microcapsules volume amount. Unlike $\mathrm{MC}_{1}$, the $\mathrm{MC}_{2}$ microcapsules tended to form large agglomerates (Figure 3a), which was a result of the microcapsule drying process (Stanković Elesini et al., 2016). The obtained sizes of the $\mathrm{MC}_{2}$ agglomerates were in the range of $5.45 \mu \mathrm{m}$ to $56.23 \mu \mathrm{m}$, with the mean microcapsule agglomerate size of $15.21 \mu \mathrm{m}$ (stdev. 7.96).

Comparing both selected types of fragranced microcapsules, $\mathrm{MC}_{1}$ and $\mathrm{MC}_{2}$, it can be concluded that the fragranced microcapsules in water suspension $\left(M_{1}\right)$ were much larger than the dry fragranced microcapsules $\left(\mathrm{MC}_{2}\right)$. According to that, it could be presumed that the microcapsules with larger diameter $-\mathrm{MC}_{1}$, would be more sensitive to shear forces than $\mathrm{MC}_{2^{\prime}}$ therefore the captured fragrance could, under certain conditions, evaporate much easier than with $\mathrm{MC}_{2}$.

- Release behaviour of the fragranced microcapsules

The microcapsules release behaviour presents the proportion of the released core material (diffusion) through the wall of the fragranced microcapsules. For that purpose, the fragranced $\mathrm{MC}_{1}$ microcapsules were put in the preheated oven at $135^{\circ} \mathrm{C}$ and left for 180 minutes (Figure 4). The analysis has shown, that the mass loss (54.3\%) after 30 minutes corresponded to the water evaporation (Šumiga, 2013), while the residue corresponded to the dry mass/share of the fragranced microcapsules in the water suspension. The mass loss within the subsequent 150 minutes corresponded to the diffusion of the core material through the microcapsule wall in the amount of $6.2 \%$.

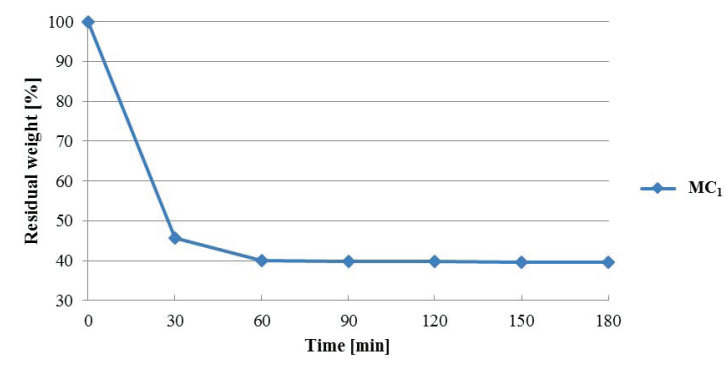

» Figure 4: Residual weight of the fragranced microcapsules in the water suspension $\left(\mathrm{MC}_{1}\right)$ during $180 \mathrm{~min}$ utes at $135^{\circ} \mathrm{C}$

\section{Varnishes}

The basic characteristics (viscosity, density, pH value and surface tension) of specifically selected varnishes $V_{1}, V_{2}$ and $V_{3}$ are presented in Table 2. In all three varnishes, the same mass concentration (1\%) of the fragranced microcapsules $\left(\mathrm{MC}_{1}\right.$ and $\left.\mathrm{MC}_{2}\right)$ was added. Due to the fact that one type of the fragranced microcapsules $-\mathrm{MC}_{1}$, was in water suspension, its viscosity and $\mathrm{pH}$ value were also determined.

The viscosity of the oil-based varnish $V_{3}$ was, as expected, the highest. The viscosity of the water-based varnishes $V_{1}$ and $V_{2}$ differed, wherein the $V_{2}$ had a higher viscosity than $V_{1}$. Results could be contributed to the different base composition of the varnishes (acrylic resin in the case of $V_{1}$ and acrylic emulsion in the case of $V_{2}$ ). In accordance with the measured results of varnishes viscosities, values of the density have been calculated.

It can be noticed that the addition of microcapsules slightly increased the viscosity, as well as the densities of all three varnishes (Table 2). This was expected due to the addition of the highly viscous fragranced microcapsules in water suspension $\left(\mathrm{MC}_{1}\right)$ ( $4.40 \mathrm{dPa} \cdot \mathrm{s}$ ) on one side and the addition of the dry fragranced microcapsules $\left(\mathrm{MC}_{2}\right)$ on the other side.

Due to the acidic nature of the microcapsules in water suspension $\left(\mathrm{MC}_{1}\right)$ their addition into the water-based varnishes $V_{1}$ and $V_{2}$ slightly decreased their $\mathrm{pH}$ values, while the addition of dry microcapsules $\left(\mathrm{MC}_{2}\right)$ increased the $\mathrm{pH}$ value of the $\mathrm{V}_{3}$ varnish and moderated its highly acidic nature.

The obtained surface tension value of the water-based varnish $V_{1}$ is the highest among the three, while the $V_{3}$ varnish showed the lowest surface tension value (Table 2). The higher surface tension values of the waterbased varnishes are the result of relatively high surface tension of water, and other components included in the varnish compositions (i.e. surface tension of water is $72 \mathrm{mN} / \mathrm{m}$ while solvent-based inks have a surface tension of 20-35 mN/m) (Lichtenberger, 2004).

\section{Table 2}

The basic characteristics of the varnishes, fragranced microcapsules and their combination

\begin{tabular}{c|c|c|c|c}
\hline Sample & $\begin{array}{c}\text { Viscosity } \\
{[\mathrm{dPa} \cdot \mathrm{s}]}\end{array}$ & $\begin{array}{c}\boldsymbol{\rho} \\
{\left[\mathrm{g} / \mathrm{cm}^{3}\right]}\end{array}$ & $\begin{array}{c}\mathbf{p H} \\
{[/]}\end{array}$ & $\begin{array}{c}\text { Surface } \\
\text { tension } \\
{[\mathrm{mN} / \mathrm{m}]}\end{array}$ \\
\hline $\mathrm{MC}$ & 4.40 & $/$ & 5.64 & $/$ \\
\hline $\mathrm{MC}_{2}$ & $/$ & $/$ & $/$ & $/$ \\
\hline $\mathrm{V}_{1}$ & 0.72 & 1.0042 & 8.35 & 30.94 \\
\hline $\mathrm{V}_{2}$ & 1.70 & 1.0160 & 7.97 & 22.39 \\
\hline $\mathrm{V}_{3}$ & 2.20 & 0.9362 & 1.32 & 21.95 \\
\hline $\mathrm{V}_{1} \mathrm{MC}_{1}$ & 0.78 & 1.0142 & 8.29 & $/$ \\
\hline $\mathrm{V}_{2} \mathrm{MC}_{1}$ & 1.75 & 1.0262 & 7.81 & $/$ \\
\hline $\mathrm{V}_{3} \mathrm{MC}_{2}$ & 2.40 & 0.9455 & 5.42 & $/$ \\
\hline & & & &
\end{tabular}




\section{Table 3}

Measured values of the thickness and the grammage of the printed samples with screen printing and coating process

\begin{tabular}{|c|c|c|c|c|c|}
\hline $\begin{array}{l}\text { Application } \\
\text { technique }\end{array}$ & Sample Property & $\begin{array}{l}\text { Thickness } \\
\qquad[\mu \mathrm{m}]\end{array}$ & $\begin{array}{l}\text { Increase of } \\
\text { thickness [\%] }\end{array}$ & $\begin{array}{c}\text { Grammage } \\
{\left[\mathrm{g} / \mathrm{m}^{2}\right]}\end{array}$ & $\begin{array}{c}\text { Increase of } \\
\text { grammage [\%] }\end{array}$ \\
\hline Unprinted & Foil & 96.90 & - & 133.11 & - \\
\hline \multirow{6}{*}{ Screen printed } & $\mathrm{SPV}_{1}$ & 139.70 & 44.17 & 140.25 & 5.36 \\
\hline & $\mathrm{SPV}_{2}$ & 135.40 & 39.73 & 157.78 & 18.53 \\
\hline & $\mathrm{SPV}_{3}$ & 122.10 & 26.01 & 167.67 & 25.96 \\
\hline & $\mathrm{SPV}_{1}-\mathrm{MC}_{1}$ & 149.70 & 54.49 & 156.11 & 17.28 \\
\hline & $\mathrm{SPV}_{2}-\mathrm{MC}_{1}$ & 139.40 & 43.86 & 160.89 & 20.87 \\
\hline & $\mathrm{SPV}_{3}-\mathrm{MC}_{2}$ & 137.40 & 41.79 & 167.78 & 26.05 \\
\hline \multirow{6}{*}{ Coated } & $\mathrm{CV}_{1}$ & 118.50 & 22.29 & 142.44 & 7.01 \\
\hline & $\mathrm{CV}_{2}$ & 135.00 & 39.32 & 162.11 & 21.79 \\
\hline & $\mathrm{CV}_{3}$ & 124.10 & 28.07 & 169.55 & 27.38 \\
\hline & $\mathrm{CV}_{1}-\mathrm{MC}_{1}$ & 125.30 & 29.31 & 161.75 & 21.52 \\
\hline & $\mathrm{CV}_{2}-\mathrm{MC}_{1}$ & 140.20 & 44.68 & 171.50 & 28.84 \\
\hline & $\mathrm{CV}_{3}-\mathrm{MC}_{2}$ & 142.80 & 47.37 & 174.92 & 31.41 \\
\hline
\end{tabular}

\section{Properties of prints}

After printing, thickness and grammage measurements of the prints were performed (Table 3). Samples printed with screen printing were designated as SP, and coated samples as C. Table 3 presents the measured values of the prints on transparent foil, which were printed and coated with all three selected varnishes $V_{1}, V_{2}$ and $V_{3}$, without and with appropriate fragranced microcapsules $\mathrm{MC}_{1}$ and $\mathrm{MC}_{2}$.

From the results in Table 3 it can be seen that screen printed (SP) and coated varnish layers (C) are much thinner than the limitations of the screen printing (128 $\mu \mathrm{m})$ and coating $(200 \mu \mathrm{m})$ (namely, in Table 3 measurements of printed varnish layers on foil samples are presented). These results could be contributed to the varnishes rheological characteristics, surface characteristics of the printing substrate (foil) and the interactions between the varnishes and the foil samples. The higher thichness in the case of varnish layers $V_{1}$ and $V_{2}$ was expected, since both varnishes had lover viscosity in comparison to varnish $V_{3}$. Consequently, the quantity of transferred varnish through the screen printing mesh was probably higher for varnishes $V_{1}$ and $V_{2}$ as in the case of oil-based varnish $V_{3}$. The whole quantity of the varnishes transferred through the mesh was distributed at the surface of the foil substrate without ability to penetrate into the foil structure.

The addition of the fragranced microcapsules $\mathrm{MC}_{1}$ and $M C_{2}$ in the varnishes $V_{1}, V_{2}$ and $V_{3}$ increased the thickness and grammage of all samples, regardless of the used application technique. This is most noticeable in the case of oil-based varnish $V_{3}$, where the thicknesses of both printed and coated varnish layers were significantly (for almost twice) increased after the addition of dry microcapsules $\mathrm{MC}_{2}$. Microcapsules (in suspension or as dry particles) were added as $1 \%$ by mass conc. which means that actual dry mas of microcapsules which were added as suspension was significantly lower as in the case of dry microcapsules. Consequently, increase in thicknes and grammage of samples SPV $-\mathrm{MC}_{2}$ and $\mathrm{CV}_{3}-\mathrm{MC}_{2}$ to which dry microcapsules were added was much bigger as in the case of $\mathrm{SPV}-\mathrm{MC}_{1} / \mathrm{CV}_{1}-\mathrm{MC}_{1}$ and $\mathrm{SPV}_{2}-\mathrm{MC}_{1} / \mathrm{CV}_{2}-\mathrm{MC}_{1}$ to which microcapsules were added in suspension (Stanković - Elesini et. al, 2016).

In order to obtain the information on microcapsules' properties in the applied varnish layers, image analyses of the SEM images were performed. Figure 5 presents the SEM images that show the surfaces and cross-sections of the screen printed samples using all three varnishes $V_{1}$, $V_{2}$ and $V_{3}$ without and with the addition of the fragranced microcapsules $\mathrm{MC}_{1}$ and $\mathrm{MC}_{2}$, where white arrows are indicating the presence of either single fragranced microcapsules or their agglomerates, respectively.

On screen printed samples SPV and SPV $-\mathrm{MC}_{1}$ similar, grainy and rough surface structure was observed. This result can be contributed to the varnish composition $\left(V_{1}\right.$ contained polyethylene wax) (Figure $5 a$ and $5 b$ ). Due to the addition of very small amount ( $1 \%$ mass conc.) of the fragranced microcapsules $\mathrm{MC}_{1}$ into the varnish SPV ${ }_{1}$ the fragranced microcapsules are hardly visible on the surface. For that reason, we have concluded that they are not the primary cause of the surface non-uniformities of the prints. Despite their low number, individual microcapsules can be noticed and separated from the particles of the polyethylene wax due to their distinguished spherical shape (Figure 5b). Agglomeration of the fragranced $\mathrm{MC}_{1}$ microcapsules was not observed. The cross-section of the printed layer $\mathrm{SPV}-\mathrm{MC}_{1}$ showed that the number of added fragranced microcapsules $M C_{1}$ is 


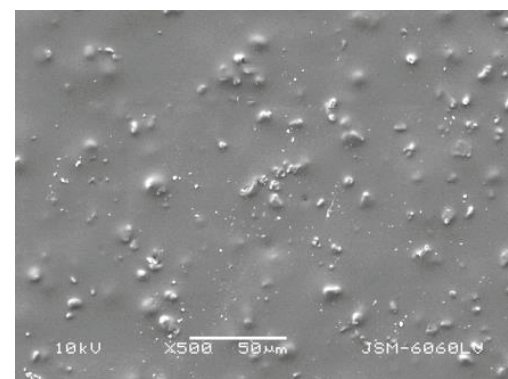

a)

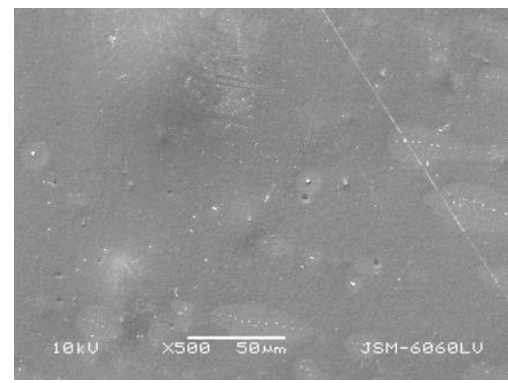

d)

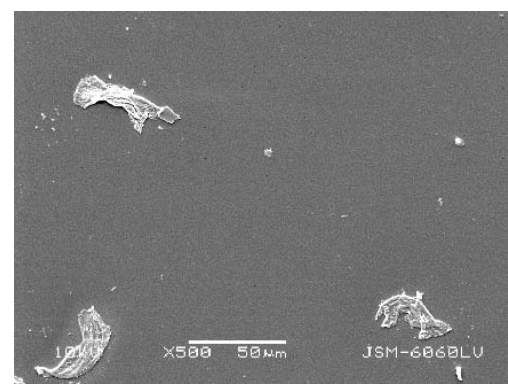

g)

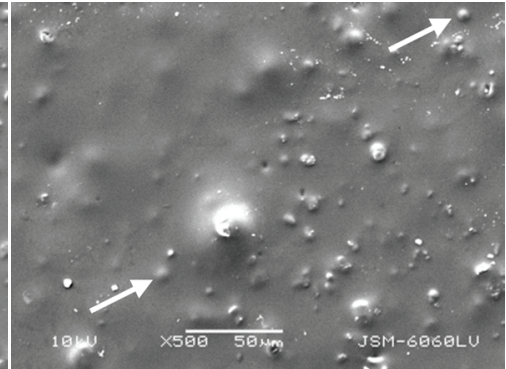

b)

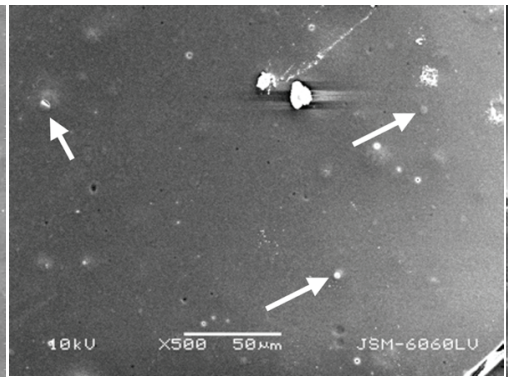

e)

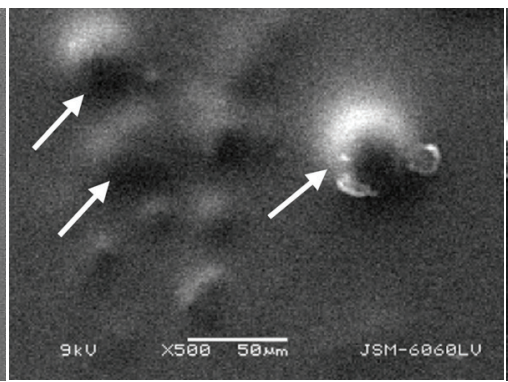

h)

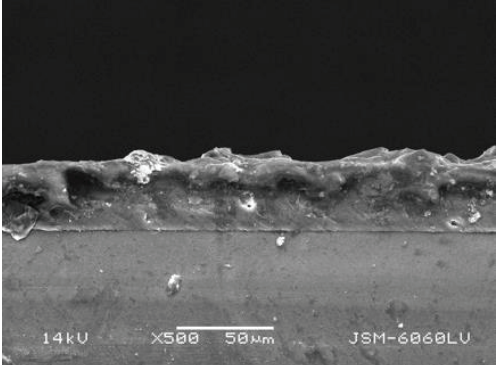

c)

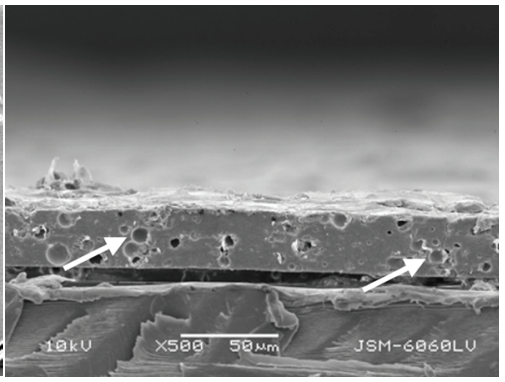

f)

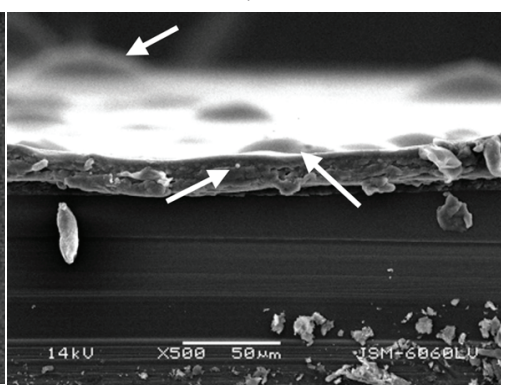

i)

» Figure 5: Surface of the screen printed samples $S P V_{1}(a), S P V_{1}-M C_{1}(b), S P V_{2}(d), S P V_{2}-M C_{1}(e), S P V_{3}(g)$ and $S P V_{3}-M C_{2}(h)$, with corresponding cross-sections of $S P V_{1}-M C_{1}(c), S P V_{2}-M C_{1}(f)$ and $S P V_{3}-M C_{2}(i)$; $S E M$; $500 \times$ magnification)

very low and therefore hardly noticeable. Another cause of difficulties in microcapsules detection is varnish characteristics which under sample preparation procedure (cutting) did not allow a sufficiently "clear" cross-section cut, which as a result hindered the region with microcapsules. However, the irregular and rough printed surface, as well as the clear boundary between the varnish layer (upper layer) and the printing substrate - transparent foil (bottom layer) is clearly visible (Figure 5c).

Unlike the prints made by SPV varnish, the surface of $\mathrm{SPV}_{2}$ relatively uniform and smooth (Figure $5 \mathrm{~d}$ ). Low but visible number of added $M C_{1}$ fragranced microcapsules into the varnish $\mathrm{SPV}_{2}-\mathrm{MC}_{1}$, can be noticed (Figure 5e). Unlike printed samples of the varnish $\mathrm{SPV}_{1}$, the prints of varnish $\mathrm{SPV}_{2}$ were very brittle, and as a result, fractures appeared on the printed surface (straight lines on Figure $5 \mathrm{~d}$ and $5 \mathrm{e}$ ). As with $\mathrm{SPV}-\mathrm{MC}_{1}$ clear boundary between the varnish layer and the foil layer on the sample $\mathrm{SPV}_{2}-$ $\mathrm{MC}_{1}$ can be observed (Figure $5 \mathrm{f}$ ). Due to the composition of the $\mathrm{V}_{2}$, the holes where the $\mathrm{MC}_{1}$ fragranced microcapsules and air bubbles were entrapped inside the printed varnish layer, can be observed. Microcapsules are relatively uniformly distributed in the printed varnish layer
$S P V_{2}-M_{1}$. The agglomeration of the $M C_{1}$ fragranced microcapsules was not observed here as well (Figure 5f).

The surface of printed oil-based varnish SPV 3 was the smoothest. Small particles of dust material (most likely the residuals of SEM sample preparation) can be noticed on the surface of the print (Figure $5 \mathrm{~g}$ ). On the surface of the prints $\mathrm{SPV}_{3}-\mathrm{MC}_{2}$ dry fragranced microcapsules $\mathrm{MC}_{2}$ and their agglomerates are visible in the varnish layer (Figure 5h). Similar as in the case of the $\mathrm{SPV}_{1}-\mathrm{MC}_{1}$ prints, fragranced microcapsules are hardly visible in the cross-section of the layer (Figure 5i), though microcapsules clusters can be observed on the surface (Figure $5 \mathrm{~h}$ and $5 \mathrm{i}$ ). From the Figure 5 it can be observed that the thickness of the screen printed sample $\mathrm{SPV}_{2}-\mathrm{MC}_{1}$ (Figure $5 \mathrm{f}$ ) is almost double the size of the $\mathrm{SPV}_{3}-\mathrm{MC}_{2}$ sample (Figure $5 \mathrm{i}$ ), though previously obtained results showed that the thicknesses of these two samples are almost the same (Table 3). The reasons for this disagreement are the presence of large microcapsules' clusters that protrude from the surface of the $\mathrm{SPV}_{3}-\mathrm{MC}_{2}$ sample (Figure $5 \mathrm{i}$ ), as well as the used thickness measurement method which included the 


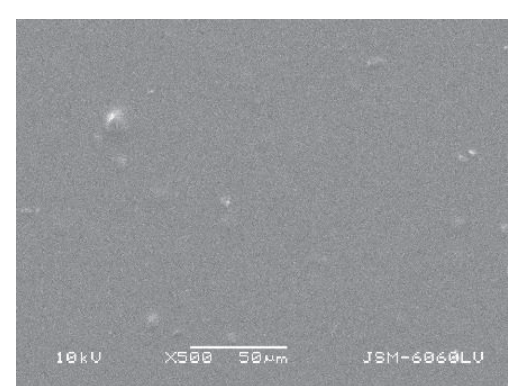

a)

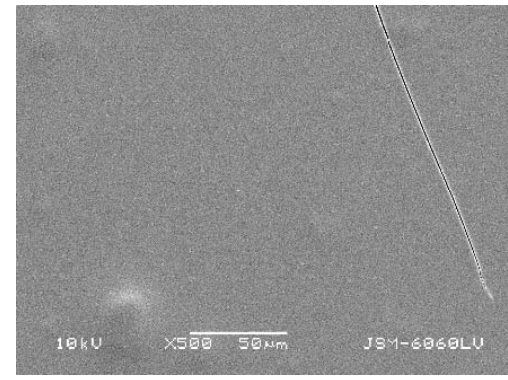

d)

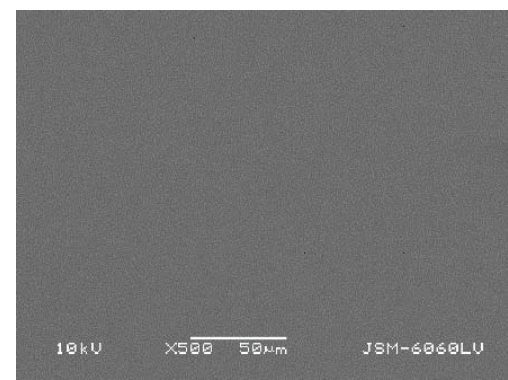

g)

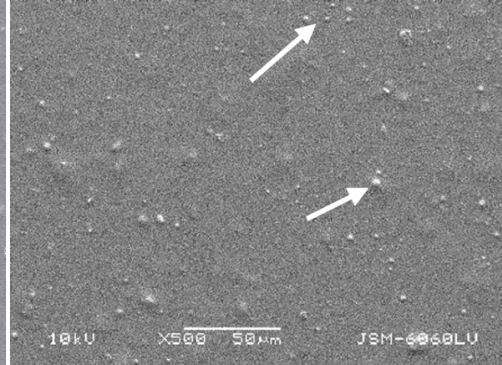

b)

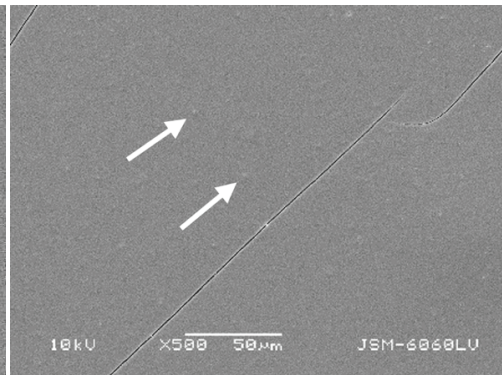

e)

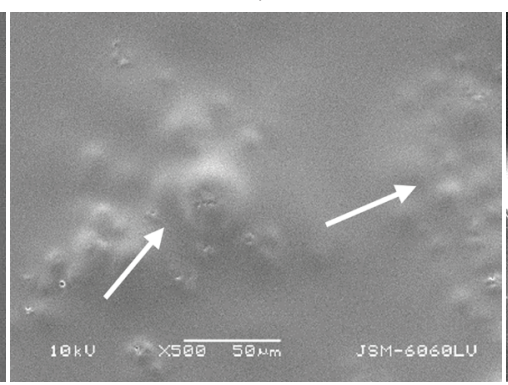

h)

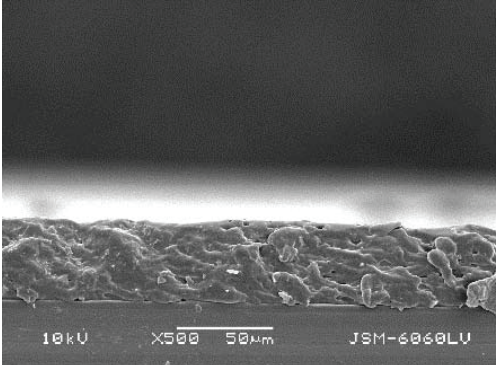

c)

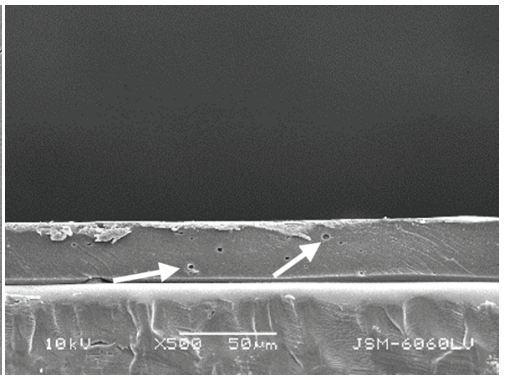

f)

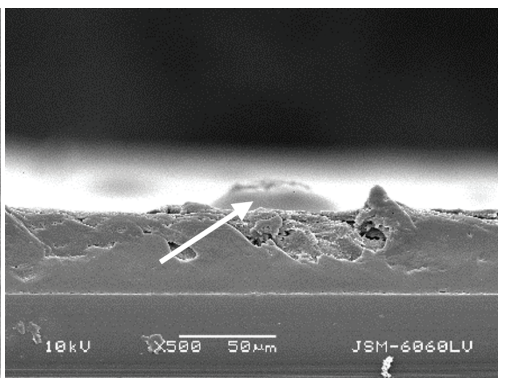

i)

» Figure 6: Surface of the coated samples CV1 (a), CV1-MC1 (b), CV2 (d), CV2-MC1 (e), CV3 (g) and CV3-MC2 (h), with corresponding cross-sections of CV1-MC1 (c), CV2-MC1 (f) and CV3-MC2 (i); (SEM; 500x magnification)

clusters in the thickness estimation as well, which consequently increased a total thickness of the sample.

In Figure 6 SEM images of the surfaces and the cross-sections of the varnish $V_{1}, V_{2}$ and $V_{3}$ prints on the foils (without and with fragranced $\mathrm{MC}_{1}$ and $\mathrm{MC}_{2}$ microcapsules) made by the coating process are presented. White arrows on the images indicate the presence of either single or agglomerated fragranced microcapsules.

The $\mathrm{CV}_{1}$ prints show very uniform surface structure, even more uniform than in the case of SPV samples $_{1}$ (Figure 6a). As it can be seen in Figure 6b. fragranced $M C_{1}$ microcapsules are clearly seen on the surface and their presence contributed to the increase of the uneven surface. Due to the relatively soft structure of the printed varnish layer, its cross-section was deformed during the preparation of the sample, and as such it disabled a detection of the $\mathrm{MC}_{1}$, although individual fragranced microcapsules can be seen (white arrow on Figure 6b. indicates the $\mathrm{MC}_{1}$ ).

The surface of the prints $\mathrm{CV}_{2}$ was more uniform compared to the surface of $\mathrm{SPV}_{2}$, though it also pos- sessed similar cracks on the surface, due to the rigid structure of dried printed samples of $V_{2}$ (Figure $6 d$ ). The addition of fragranced microcapsules $M_{1}$ can be noticed on the surface as well as in the cross-section of the print (Figure 6e and 6f) with the relatively uniform distribution. A smaller number of the $M C_{1}$ fragranced microcapsules as well as the entrapped air bubble cavities, as a result of the coating process, were detected in the cross-section of the $\mathrm{CV}_{2}-\mathrm{MC}_{1}$ sample compared to the $\mathrm{SPV}_{2}-\mathrm{MC}_{1}$ sample (Figure $6 \mathrm{f}$ ).

The samples of $\mathrm{CV}_{3}$ prints showed the greatest surface uniformity (Figure 6g), while higher magnification revealed a larger number of both, the fragranced $\mathrm{MC}_{2}$ microcapsules and their agglomerates in compared to the samples $\mathrm{CV}_{2}$ and $\mathrm{CV}_{2}-\mathrm{MC}_{1}$ (Figure $6 \mathrm{~h}$ ). The clustering e.g. agglomeration of the microcapsules disabled the detection of individual microcapsules (Figure $6 \mathrm{~h}$ and 6i).

The prints made with $\mathrm{V}_{2}$ varnish $\left(\mathrm{SPV}_{2}-\mathrm{MC}_{1}\right.$ and $\left.\mathrm{CV}_{2}-\mathrm{MC}_{1}\right)$ possessed the most uniform surface structure, regardless of the application technique, because the added fragranced microcapsules were placed just slightly below the varnish surface compared to the microcapsules 
position in the prints made with other two varnishes $V_{1}$ and $\mathrm{V}_{3}\left(\mathrm{SPV} \mathrm{V}_{1}-\mathrm{MC}_{1}, \mathrm{SPV}-\mathrm{MC}_{2}, \mathrm{CV}_{1}-\mathrm{MC}_{1}\right.$ and $\left.\mathrm{CV}_{3}-\mathrm{MC}_{2}\right)$.

\section{Conclusions}

Based on the measurements of the printing material properties and visual SEM analysis, several conclusions can be made.

As a result of the addition of the fragranced microcapsules $M C_{1}$ and $M C_{2}$ into the varnishes $V_{1}, V_{2}$ and $V_{3}$, the viscosity and density of all three varnishes increased. The addition of $M C_{1}$ and $M_{2}$ led to a slight decrease of $\mathrm{pH}$ value in the case of water-based varnishes $V_{1}$ and $V_{2}$, while the addition of the dry microcapsules $\mathrm{MC}_{2}$ into the oil-based $\mathrm{V}_{3}$ varnish resulted in increase of $\mathrm{pH}$ value. Regarding the surface tension of the varnishes, water-based varnishes $V_{1}$ and $V_{2}$ showed a higher value of the surface tension compared to the oil-based $V_{3}$.

Obtained thicknesses of the varnish layers were much lower that the limitations of the screen printing (128 $\mu \mathrm{m})$ and coating process possibilities $(200 \mu \mathrm{m})$. This fact could be contributed to the rheological characteristics of the varnishes as well as the surface characteristics of the used printing substrate - transparent foil, the drying speed of the varnishes, and the interactions between the applied varnishes and the printing substrate. The addition of the fragranced microcapsules in the varnishes increased the thicknesses and the grammages of all samples, irrespective of the microcapsules type (either $\mathrm{MC}_{1}$ or $\mathrm{MC}_{2}$ ) and the used application technique (screen printing or coating process).

The fragranced microcapsules in water suspension $\mathrm{MC}_{1}$ had very regular, spherical shape and smooth surface, though their sizes were not uniform. This caused a wide diameter size distribution (the mean diameter was 4.44 $\mu \mathrm{m})$. The shape of the fragranced dry microcapsules $\mathrm{MC}_{2}$ was regular, and their sizes were ununiform, though this was less pronounced compared to the $\mathrm{MC}_{1}$ fragranced microcapsules, hence $\mathrm{MC}_{2}$ had narrower and more uniform size distribution. The mean diameter of the $\mathrm{MC}_{2}$ was $2.39 \mu \mathrm{m}$. Dry fragranced microcapsules tended to form large agglomerates (the mean microcapsule agglomerate size was $15.21 \mu \mathrm{m}$ ), as a result of the drying process (Stanković- Elesini et al., 2016) and their specific characteristics (e.g. viscosity, drying speed). In the case of the addition of the fragranced microcapsules in water suspension $\mathrm{MC}_{1}$ into the varnishes $\mathrm{V}_{1}$ and $\mathrm{V}_{2}$, the clustering of the fragranced microcapsules was not observed.

The addition of the fragranced microcapsules in all three varnishes $\left(V_{1}, V_{2}\right.$ and $\left.V_{3}\right)$ led to the increase of the surface roughness of the printed and coated varnish layers. The SEM image analyses showed that the higher surface uniformity of the prints is obtained by the coating process compared to the screen printing, where after lifting the printing form from the printing surface air bubbles appear and form regular gaps pattern in the dried printed varnish layer.

The research has shown that the use of the water-based varnish $2\left(V_{2}\right)$ was not suitable for the screen printing and coating process of varnish samples with the addition of fragranced microcapsules (SPV $-\mathrm{MC}_{1}$ and $\mathrm{CV}_{2}-\mathrm{MC}_{1}$ ), because, regardless of the microcapsules addition, the dried printed and coated varnish layers were very brittle, causing the formation of cracks and ruptures of the printed surface. Regarding the fact that the scent entrapped inside the fragranced microcapsules can be released only by the application of the shear force in/or mechanical pressure this type of varnish is not suitable. In addition to mentioned, the fragranced microcapsules in $V_{2}$ varnish printed layer were generally positioned below the surface (mainly in the central area), which could hinder the activation of the fragranced microcapsules and thus disabling their basic function.

For detailed analyses how the printing technique influences the properties of prints made with varnishes and fragranced microcapsules other techniques such as pad printing, flexography, offset lithography, etc. should be investigated. Research should be pointed towards the investigation of the fragranced microcapsules characteristics in the printed layers of varnish as well as printing inks, i.e. microcapsules spatial distribution in the applied varnish or ink layers. Beside mentioned the preparation methods for image analyses, which would improve this microcapsule feature in the final prints, need to be improved. Microcapsules spatial distribution in the printed ink/varnish layer would give important information about the microcapsules "functionality potential", and it could reveal the effect of the printing material properties and characteristics (varnish or ink, fragranced microcapsules, printing substrate) and selected printing techniques on the improved properties of prints.

\section{Acknowledgements}

This research was supported by the Serbian Ministry of Science and Technological Development, Grant No.:35027 "The development of software model for improvement of knowledge and production in the graphic arts industry", and by Cinkarna Celje, which provided the varnishes for the experimental part of the research.

\section{References}

Arshady, R. \& Boh, B. (2003) Microcapsule applications: patent and literature analysis. Microcapsule patents and products.; The MML series, Vol. 6, Citus reference series, London, pp. 85-156. 
Boh, B. (2007) Developpements et applications industrielles des microcapsules. V: Van Damme, T.F. (ur.): Microencapsulation: des sciences aux technologies. Paris, Lavoisier, pp. 9-22.

Boh, B., Hodzar, D., Knez, E., Kuković, M., Pipal, V. \& Voda, K. (1999) Development of microcapsules for textile finishing. In: Glavic, P., Brodjnak-Voncina, D. (eds.), Zb. Ref. Posvetovanja Slov. Kem. Dnevi, Maribor, Slovenia. Maribor, University of Maribor. pp. 762-767.

Boh, B. \& Šumiga, B. (2008) Microencapsulation technology and its applications in building construction materials. Materials and Geoenvironment. 55 (3), 329-344. Available from: http:// www.rmz-mg.com/letniki/rmz55/RMZ55_03290344.pdf [Accessed 12th September 2016].

Chen, B., Hashimoto, T., Vergeer, F., Burgess, A., Thompson, G. \& Robinson I. (2014) Three-dimensional analysis of the spatial distribution of iron oxide particles in a decorative coating by electron microscopic imaging. Progress in Organic Coatings. 77 (6), 1069-1072. Available from: doi: 10.1016/j. porgcoat.2014.03.005 [Accessed 22th September 2016].

Chovancova, V., Pekarovicova, A. \& Fleming, I. P. (2005) Production of 3D Structures in Printing. In: Claypole, T. (ed.) Technical Association of the Graphic Arts. TAGA 2005: 57th Annual Technical Conference of the Technical Association of the Graphic Arts: Proceedings of the 57th TAGA Annual Technical Conference, TAGA 2005, 17-20 April 2005, Toronto, Canada. Pittsburgh, TAGA. pp. 93-94.

Daerr, A. \& Mogne, A. (2016) Pendent_Drop: An ImageJ Plugin to Measure the Surface Tension from an Image of a Pendent Drop. Journal of Open Research Software. 4 (1), 1-5. Available from: doi: 10.5334/jors.97 [Accessed 22th September 2016].

Dubey, R., Shami, T. C. \& Bhasker, Rao K. U. (2009) Microencapsulation technology and applications. Defence Science Journal. 59 (1), 82-95. Available from: doi: 10.14429/dsj.59.1489 [Accessed 22th September 2016].

Gosh, S. K. (2000) Functional Coatings and Microencapsulation. Weinheim, Wiley- $\mathrm{VCH}$.

Goetzendorf-Grabowska, B. Krolikowska, H., Bak, P., Gadzinovski, M., Brycki, B. \& Szwajca, A. (2008) Triclosan Encapsulated in Poli(L,L-lactide) as a Carrier of Antibacterial Properties of Textiles. Fibres \& Textiles in Eastern Europe. 3 (68), 102107. Available from: http://www.fibtex.lodz.pl/ file-Fibtex_(tldoddl3obozzy6w).pdf-FTEE_68_102. pdf [Accessed 22th September 2016].

Goetzendorf-Grabowska, B., Krolikowska, H. \& Gadzinowski, M. (2004) Polymer Microspheres as Carriers of Antibacterial Properties of Textiles: A preliminary Study. Fibres \& Textiles in Eastern Europe. 12 (4), 62-64. Available from: http://www.fibtex.lodz. pl/48_16_62.pdf [Accessed 22th September 2016].
ImageJ (2004) [Online] Download. Available from: https://imagej.nih.gov/ij/download.html [Accessed 29th June 2016].

International Organization for Standardization (1990) ISO 8791-2:1990. Paper and board - Determination of roughness/smoothness (air leak methods) - Part 2: Bendtsen method. Geneva, International Organization for Standardization.

International Organization for Standardization (1996) SIST EN ISO 5084:1996. Textiles - determination of thickness of textiles and textile products. Geneva, International Organization for Standardization.

International Organization for Standardization (2012) ISO 536:2012. Paper and board - Determination of grammage. Geneva, International Organization for Standardization.

Kipphan, H. (2001) Handbook of Print Media. New York, Springer.

Kuković, M. \& Knez, M. (1998) Process for preparing carriers saturated or coated with microencapsulated scents. W01996009114 (Patent).

Kulčar, R., Friškovec, M., Hauptman, N., Vesel, A. \& Klanjšek- Gunde, M. (2010) Colorimetric properties of reversible thermochromic printing inks. Dyes and Pigments. 86 (3), 271-277. Available from: doi: 10.1016/j. dyepig.2010.01.014 [Accessed 22th September 2016].

Lichtenberger, M. (2004) Inks - Water-Based. Available from: http://davidlu.net/Matt. pdf [Accessed 29th April 2017].

Maekawa, Y., Miyano, S., Yazawa, K. \& Kondo, A. (1975) Aqueous printing ink containing perfume-containing microcapsules. US3888689 A (Patent).

McShane, M. \& Ritter, D. (2010) Microcapsules as optical biosensors. Journal of Materials Chemistry. 20 (38), 8189-8193. Available from: doi: 10.1039/ COJM01251C [Accessed 29th April 2017].

MikroCaps (2013) MikroCaps Fragrances. Available from: http://mikrocaps.com/products/microencapsulated-fragrances/ [Accessed 4th April 2017].

Microtek Laboratories, Inc. (2015) Technical overview: Microencapsulation. Available from: http:// www.microteklabs.com/technical-overview. html [Accessed 24th September 2015].

Nelson, G. (2001) Microencapsulation in textile finishing. Coloration Technology. 31 (1), 57-64. Available from: doi: 10.1111/j.1478-4408.2001. tb00138.x [Accessed 29th April 2017].

Ocepek, B., Boh, B., Šumiga, B. \& Tavčer, P. F. (2012) Printing of antimicrobial microcapsules on textiles. Coloration Technology. 128 (2), 95-102. Available from: doi: 10.1111/j.14784408.2011.00349.x [Accessed 29th April 2017].

Pavlović, Ž. Dedijer, S. Stankovič- Elesini, U. \& Urbas, R. (2014) Structure of microcapsules and its use in the industry - overview. In: Novaković, D. (ed.) GRID 2014: International Symposium on Graphic Engineering and Design: Proceedings of the 7th International Symposium GRID 2014, 
13-14 November 2014, Novi Sad, Serbia. Novi Sad, Faculty of Technical Sciences. pp. 65-70.

Peña, B., Casals, M., Torras, C., Gumí, T. \& Garcia-Valls, R. (2009) Vanillin release from polysulfonemacrocapsules. Industrial and Engineering Chemistry Research. 48 (3), 1562-1565. Available from: doi: 10.1021/ie801133f [Accessed 29th April 2017].

Poncelet, D. \& Boh, B. (2008) Microcapsules deliver. Chemistry \& Industry. 2, 23-25.

Rodrigues, S. N., Martins, I. M., Fernandes, I. P., Gomes, P. B., Mata, V. G., Barreiro, M. F. \& Rodrigues, A. E. (2009) Scentfashion ${ }^{\circledR}$ : Microencapsulated perfumes for textile application. Chemical Engineering Journal. 149 (1-3), 463-472. Available from: doi: 10.1016/j. cej.2009.02.021 [Accessed 29th November 2016].

Rose, H. (2007) Scent Encapsulated in Printed Products. New Technologies and Economic Developments. Available from: https://projekt.beuth-hochschule. de/fileadmin/projekt/sprachen/sprachenpreis/ erfolgreiche_beitraege_2007/1._Preis_07_-_ Scent_Encapsulated_in_Printed_Products_Heike_Rose.pdf [Accessed 04th March 2017].

Sensor Products Inc. (2015) Tactile Pressure Indicating Sensor Film. Available from: https://www. sensorprod.com/prescale/product-pages/prescale/prescale.pdf [Accessed 4th April 2017].

Starešinič, M., Šumiga, B. \& Boh, B. (2011) Microencapsulation for Textile Applications and Use of SEM Image Analysis for Visualisation of Microcapsules. Tekstilec. 54 (4-6), 80-103. Available from: http:// www.tekstilec.si/wp-content/uploads/2011/04/
Mikrokapsuliranje-za-tekstilno-uporabo-in-uporaba-analize-SEM-posnetkov-za-vizualizacijo-mikrokapsul.pdf [Accessed 29th November 2016].

Stankovič- Elesini, U., Leskovšek, M., Bernik, S., Šumiga, B.\& Urbas, R. (2016) Influence of co-current spray drying conditions on agglomeration of melamine-formaldehyde microcapsules. Drying Technology. 34 (12), 1510-1520. Available from: doi: 10.1080/07373937.2015.1131713 [Accessed 29th November 2016].

Šumiga, B. (2013) Informational approaches in the design of chemical microencapsulation processes. PhD thesis. University of Ljubljana.

Urbas, R., Pavlović, Ž., Draganov, S. \& Stankovič - Elesini, U. (2014) In: Novaković, D. (ed.) GRID 2014: International Symposium on Graphic Engineering and Design: Proceedings of the 7th International Symposium GRID 2014, 13-14 November 2014, Novi Sad, Serbia. Novi Sad, Faculty of Technical Sciences. pp. 51-58.

Urbas, R. \& Stanković - Elesini, U. (2015) Color differences and perceptive properties of prints made with microcapsules. Journal of Graphic Engineering and Design. 6 (1), 15-21. Available from: www.grid.uns.ac.rs/jged/download.php?fid=152 [Accessed 29th November 2016].

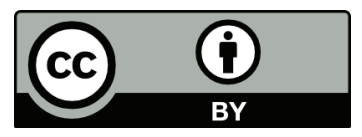

(C) 2017 Authors. Published by the University of Novi Sad, Faculty of Technical Sciences, Department of Graphic Engineering and Design. This article is an open access article distributed under the terms and conditions of the Creative Commons Attribution license 3.0 Serbia (http://creativecommons.org/licenses/by/3.0/rs/). 